\title{
TWO CASES OF DIGITALIS POISONING
}

\author{
BY \\ K. DOUGLAS WILKINSON \\ From the Birmingham United Hospital \\ Received October 14, 1941
}

In 1785 Dr. William Withering of Birmingham wrote, “ The Foxglove when given in very large and quickly repeated doses, occasions sickness, vomiting, purging, giddiness, confused vision, objects appearing green or yellow; increased secretion of urine, with frequent motions to part with it, and sometimes inability to retain it; slow pulse, even as slow as 35 in a minute, cold sweats, convulsions, syncope, death. I am doubtful whether it does not sometimes excite a copious flow of saliva.

"When given in a less violent manner, it produces most of these effects in a lower degree; and it is curious to observe that the sickness with a certain dose of the medicine does not take place for many hours after its exhibition has been discontinued; that the flow of urine will often precede, sometimes accompany, frequently follow the sickness at the distance of some days, and not unfrequently be checked by it. The sickness thus excited is extremely different from that occasioned by any other medicine; it is peculiarly distressing to the patient; it ceases, it recurs again as violent as before; and thus it will continue to recur for three or four days, at distant and more distant intervals.

"At first I thought it necessary to bring on and continue the sickness, in order to ensure the diuretic effects. Therefore my patients were ordered to persist until the nausea came on, and then to stop. But it soon appeared that the diuretic effects would often take place first, and sometimes be checked when the sickness or a purging supervened.

"The direction was therefore enlarged thus-Continue the medicine until the urine flows, or the sickness or purging take place. I found myself safe under this regulation for two or three years; but at length cases occurred in which the pulse would be retarded to an alarming degree, without any other preceding effect.

"The directions therefore required an additional attention to the state of the pulse, and it was moreover of consequence not to repeat the doses too quickly, but to allow sufficient time for the effects of each to take place, as it was found very possible to pour in an injurious quantity of the medicine before any of the signals for forbearance appeared.

" Let the medicine therefore be given in the doses, and at the intervals mentioned above:--let it be continued until it either acts upon the kidneys, the 
stomach, the pulse, or the bowels; let it be stopped upon the first appearance of any of these effects, and I will maintain that the patient will not suffer from its exhibition, nor the practitioner be disappointed in any reasonable expectation.

"From some cases, which have occurred in the course of the present year, I am disposed to believe that the digitalis may be given in small doses, viz., two or three grains a day, so as gradually to remove a dropsy, without any other than mild diuretic effects, and without any interruption to its use until the cure be completed.

"If inadvertently the doses of the Foxglove should be prescribed too largely, exhibited too rapidly, or urged to too great a length, the knowledge of a remedy to counteract its effects would be a desirable thing."

Withering used the Foxglove to promote diuresis; his dosage was so admirable that it remains to-day the standard in general use. His directions were so simple that they cannot be improved, and he was well acquainted with digitalis poisoning, yet did not succeed in impressing upon his contemporaries the importance of the cautious doses he recommended. It is said that Dr. J. Lettson employed the medicine so incautiously that he killed several patients, and certainly many physicians regarded the digitalis as a dangerous drug.

Since Withering wrote we have learned of the active principles of digitalisthe glucosides-and of their action upon the myocardium for which they have a peculiar chemical affinity. Now we use digitalis chiefly in auricular fibrillation with the object of limiting the frequency of the ventricular contraction, prolonging the diastolic pauses, and so improving the nutrition of the heart.

These effects result from the blocking of impulses from the auricles travelling in the A-V bundle. Adequate doses of digitalis may cause complete heart block, either in auricular fibrillation or in sinus rhythm, and high grades of auriculo-ventricular dissociation can be produced relatively easily in hearts that have been damaged by rheumatism. The chemical affinity of digitalis glucosides for the myocardium is much greater than that of strophanthin, so that the effects of digitalis are much more lasting, poisoning may persist for a long time after the discontinuance of the drug, and as yet we have not found the antidote for which Withering hoped.

Even to-day digitalis is still used in dangerous doses, and in the hope of producing impossible results in unsuitable cases, so that poisoning is not uncommon. Marked slowing of the pulse rate and coupling as a result of the appearance of ventricular extrasystoles are the first two cardiac signs of digitalis intoxication. In the two cases here reported there was also widening of the QRS complexes.

\section{FIRST CASE}

Winifred B., aged 27, gave a history of rheumatic fever at the age of 10 , goitre during adolescence, appendicectomy at the age of 18 , but otherwise had enjoyed good health until July 1940 . Then six-and-a-half months pregnant with her second child, she began to have attacks of paroxysmal tachycardia. 

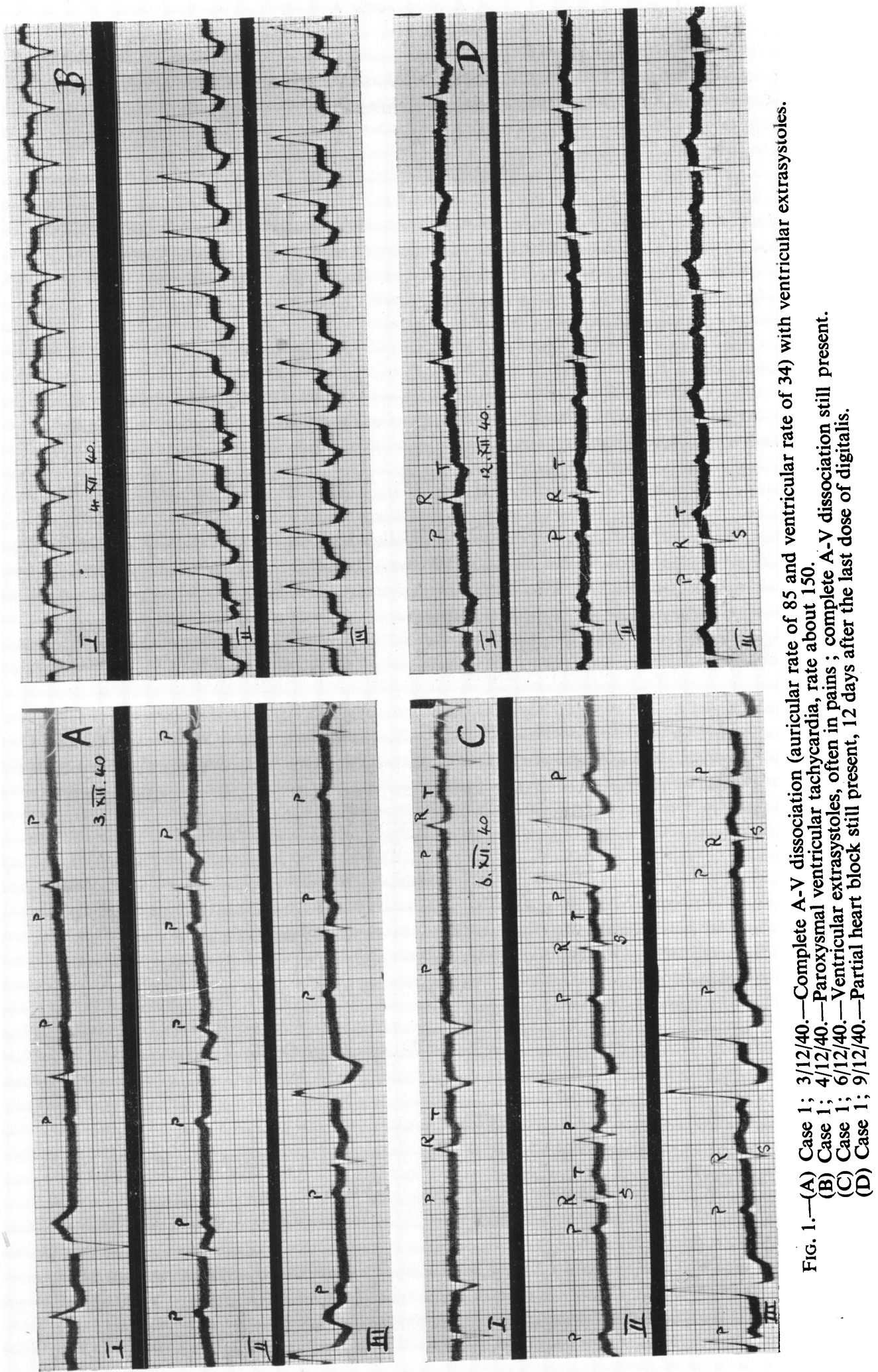
She was admitted to the Maternity Hospital, where she had a normal delivery, after which the attacks ceased; but a month or so later started again, and on November 27 she was ordered two grains of digitalis leaf every three hours. This she continued to take conscientiously until the day of admission, in spite of the persistence of the attacks of palpitation, nausea, vomiting, and disturbed vision.

When admitted to hospital, under my colleague Professor L. G. Parsons, on December 2, 1940, she was most gravely ill, but was not breathless nor cyanosed. The cardiac impulse could not be felt, the pulse was of small volume, infrequent (less than 50 per minute), and irregular with coupled beats. The tongue was furred and vomiting was frequent; in fact nausea almost prevented her taking anything by mouth and she had to be given rectal saline.

The electrocardiogram taken the day after admission showed a sinus rate of about 85 , the $\mathrm{P}$ waves being small but quite easily identified; the ventricular rate was variable, about 34 per minute, and there were ventricular extrasystoles of constant form. There was complete auriculo-ventricular dissociation (Fig. 1A).

The paroxysms of ventricular tachycardia, for which the heroic doses of digitalis folia were prescribed in this case, were not modified by the large doses, for the attacks continued, and Fig. 1B shows such an attack on December 4, on which day her heart suddenly changed from an irregular rate of about 40 per minute to a regular rate of nearly 150 ; this attack only lasted about half an hour, and ceased as abruptly as it began, but she had several subsequent attacks.

Sometimes the ventricular extrasystoles occurred in pairs, which varied in form and appeared to arise from different foci; they were separated by a constant interval. This condition is well seen in Fig. 1C, where each normal ventricular complex is followed by two ventricular extrasystoles. Complete heart block appears to be present on this date also.

On December 8 she was given quinidine sulphate in doses of three grains every two hours for five doses, and this led to an improvement in that the paroxysms of tachycardia ceased; but the persistence of digitalis block is well seen in the record taken on December 12, where the rate has become regular at 64 per minute; the P-R interval was still $0.32 \mathrm{sec}$., although the digitalis had been stopped twelve days earlier (Fig. 1D). Subsequently she gradually improved and was discharged as cured on January 30, 1941.

\section{SECOND CASE}

But adequate doses of digitalis can produce even greater changes in the electrocardiogram than those shown in the first case.

The second patient, William H., aged 57, was admitted under Professor W. H. Wynn on March 21, 1941.

He also gave a history of acute rheumatism as a child, but served in the Army from 1914 to 1920. He had appendicitis in 1933, and in 1939 was admitted to hospital with congestive heart failure. He recovered and returned 

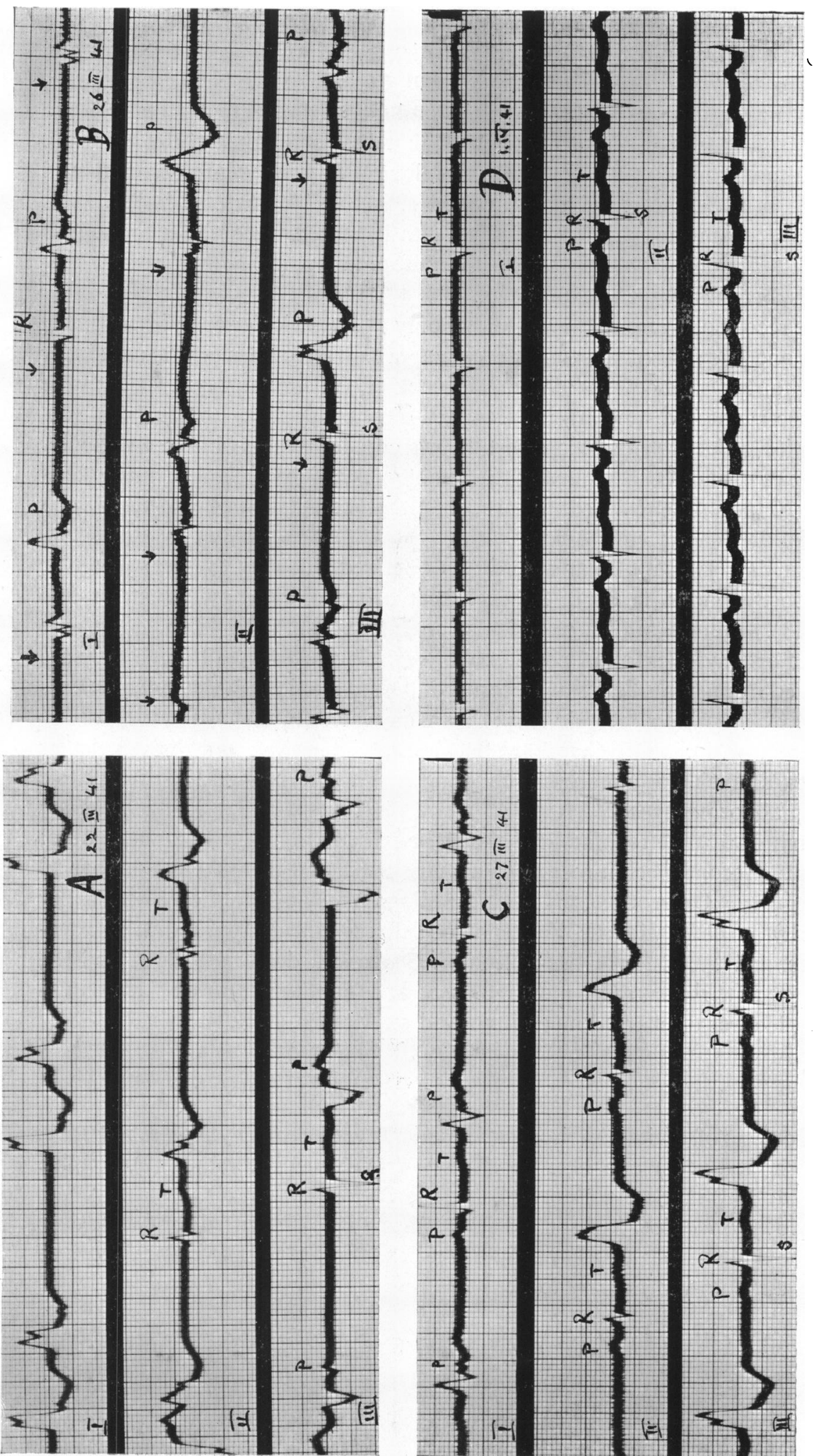

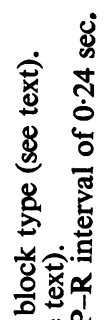

象递

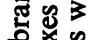

๑高势

행휴요

능혀응

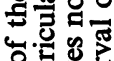

过范要

象证

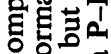

8 造

范品卷

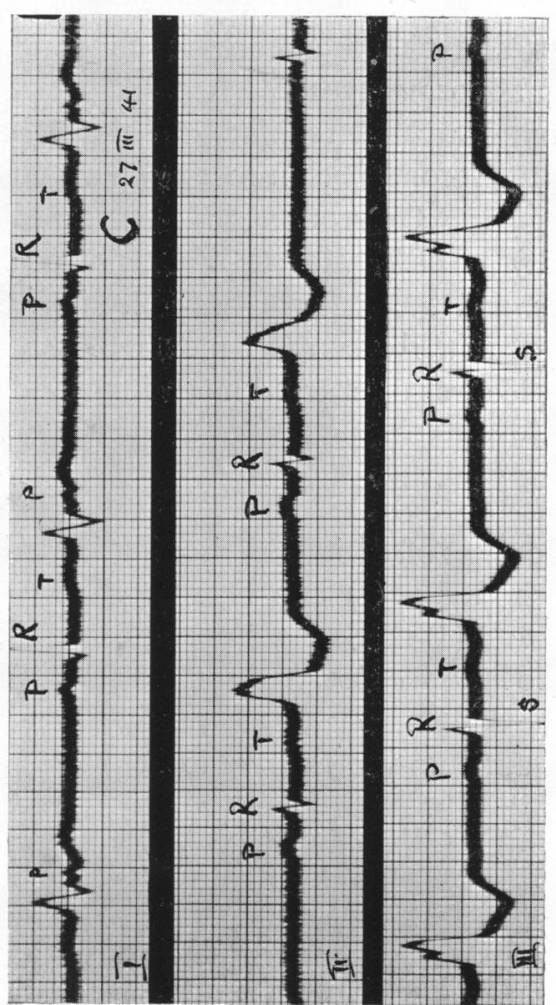

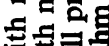

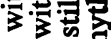

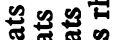

ซึ马

उृत्र

음육

ช०००

11

守过

तुํำ

तेंतेंत

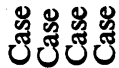

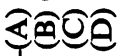

i

它

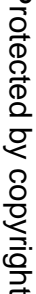


to work. In December 1940, he became distressed by increasing dyspnœa and began to have some œdema of the legs. On admission he was plethoric, œdematous, cyanosed, and orthopnœic, and weighed 12 stone 7 pounds (the degree of œdema was shown by the fact that he lost 3 stone in sixteen days). The pulse was infrequent (about 50 per minute), of poor volume, and showed coupled beats. The blood pressure was 175/110. The cardiac impulse was five inches from the mid-line in the seventh left interspace; the heart sounds were distant and he was extremely ill. Before admission he had been taking digitalis, but the dosage was unknown.

The record of March 22, 1941, shows only two ventricular complexes (one in lead II and one in lead III) that are even approximately normal; the remainder appear fairly typical of bundle branch block of the common type, being wide $(0 \cdot 16 \mathrm{sec}$.$) , notched, and having \mathrm{T}$ waves directed opposite to the initial deflection (Fig. 2A). This record also shows coupled beats, while the auricular complexes cannot be identified with certainty, but since the ventricular rate is about 30 per minute it seems probable that complete auriculo-ventricular dissociation was present.

Four days later a similar record was obtained, showing the nearly regular ventricle with a frequency of 30 , each beat being followed by an extrasystole (Fig. 2B). Here again the ventricular complexes, both the initial complexes and the extrasystoles, show considerable variation in form, although they are separated by an almost constant interval of $0.6 \mathrm{sec}$., and the auricular complexes can only be identified occasionally: but a day later (Fig. 2C), $P$ waves can be seen, the P-R interval being about $0.24 \mathrm{sec}$. and constant, and the ventricular complexes much less abnormal; coupling is still present, and the extrasystole is of an abnormal type.

From March 21 to March 28 the pulse varied from 70 to 32 per minute; during the second week it rose to an average of 80 , and thereafter was above 80 and regular. On April 1, his electrocardiogram (Fig. 2D) showed a regular sinus rhythm of 77 with a P-R interval of 0.20 sec., the disappearance of extrasystoles, and a constant QRS deflection: S was still deep in leads II and III, but QRS now measured at most 0.09 sec., and T although rather flat was upright. He was discharged much improved on May 24, 1941.

\section{SUMMARY AND CONCLUSIONS}

Two cases of digitalis poisoning in patients with sinus rhythm are recorded. Each showed : (1) complete auriculo-ventricular dissociation; (2) coupled beats; and (3) marked abnormalities in the QRS-T complexes.

Recovery was slow and some degree of heart block persisted for twelve days after the digitalis was discontinued. One case showed bundle branch block as well as auriculo-ventricular block. 